\title{
Interactions Between the Lateral Hypothalamus and the Periaqueductal Gray
}

\author{
Michael M. Behbehani, ${ }^{1}$ Melburn R. Park, ${ }^{2}$ and Mark E. Clement ${ }^{1}$ \\ 'Department of Physiology and Biophysics, University of Cincinnati, College of Medicine, Cincinnati, Ohio 45267, and \\ ${ }^{2}$ Department of Anatomy and Neurobiology, University of Tennessee at Memphis, College of Medicine, Memphis, \\ Tennessee 38163
}

\begin{abstract}
Anatomical and physiological experiments were conducted to characterize the interactions between the lateral hypothalamus (LH) and the periaqueductal gray (PAG) and to determine the role of neurotensin in their interaction. Anatomical studies using injection of Phaseolus vulgaris leucoagglutinin into the LH showed an extensive projection to the ventromedial and the ventrolateral PAG and a less dense projection to the medial and dorsal parts of this region. Physiological experiments were performed on both deeply and lightly anesthetized animals. Electrical stimulation of the $\mathrm{LH}$ caused excitation of PAG cells with an onset latency of approximately $14 \mathrm{msec}$. There was a strong correlation between the response of PAG cells to electrical stimulation and injection of glutamic acid into the LH. Electrical or chemical stimulation of the LH produced an increase in tail flick latency in the lightly anesthetized animals that outlasted the stimulation period. There was a strong correlation between the response of PAG cells to electrical and chemical stimulation of the LH and their response to pressure-injected neurotensin. It is concluded that an excitatory projection from the LH to PAG exists which may involve neurotensin. This pathway may be involved in the analgesia produced by LH stimulation.
\end{abstract}

Since the original study by Reynolds (1969), there has been a significant interest in the role of the periaqueductal gray (PAG) in pain inhibition (Mayer et al., 1971; Gebhart et al., 1983; Sandkuhler and Gebhart, 1985). Behavioral and physiological studies have shown that electrical and chemical stimulation of PAG produce analgesia that is relayed in part through the rostral ventral medulla (Basbaum et al., 1978; Behbehani and Fields, 1979) and subsequently inhibits nociceptive neurons in the dorsal horn (Basbaum et al., 1977; Bennett and Mayer, 1979; Fields et al., 1983; Sandkuhler and Gebhart, 1985). Although the role of PAG in descending pain inhibition has been established, it is not known how PAG neurons are activated under natural conditions or what transmitters are involved in the activation of these cells. Anatomical studies have established that there is a significant projection from the lateral hypothalamus $(\mathrm{LH})$ to the PAG (Grofova et al., 1978; Krieger et al., 1979; Beitz, 1982;

\footnotetext{
Received Apr. 1, 1987; revised Dec. 10, 1987; accepted Dec. 21, 1987.

Supported by USPHS Grant NS 20643 to M.M.B. and USPHS Grant NS 20841 to M.R.P.

Correspondence should be addressed to Michael M. Bchbehani at the above address.
}

Copyright (C) 1988 Society for Neuroscience $0270-6474 / 88 / 082780-08 \$ 02.00 / 0$
Mantyh, 1982). Therefore, it is likely that this pathway is involved in the activation of PAG.

Recently we have shown that injection of neurotensin (NT) into the PAG produces strong and long-lasting analgesia that is not reversed by naloxone (Behbehani and Pert, 1984). Since there are NT-containing cell bodies in the I.H (Kahn et al., 1980; Jennes et al., 1982) and some of these cells project to the PAG (Shipley et al., 1985), it is possible that activation of the LH may cause release of NT into the PAG and thereby activate these neurons. To demonstrate the projection from $\mathrm{LH}$ to $\mathrm{PAG}$ we have used injection of Phaseolus vulgaris leucoagglutin (PHAL) into the LH in order to fill the cells and their fibers in this region and have examined the morphology of the fibers originating from these cells that terminate within the PAG. In physiological studies we have compared the response of PAG cells to electrical and chemical stimulation of the $\mathrm{LH}$ and their response to NT.

\section{Materials and Methods}

Male Sprague-Dawley rats weighing 220-300 gm were used in the physiological experiments. Two types of preparations were used. In the first series of experiments, animals were anesthetized with $400 \mathrm{mg} / \mathrm{kg}$ chloral hydrate and were maintained in deep anesthesia with additional intravenous injections of chloral hydrate. After cannulation of the femoral vein, animals were stationed in a stereotaxic instrument. The skull over the PAG, medulla, and hypothalamus was removed, and the brain was covered with $2 \%$ agar in saline or saline-soaked Gel Foam. Single-unit recording was made from PAG neurons using a glass electrode (8-12 $\mathrm{M} \Omega$ ) filled with $2 \mathrm{gm} \%$ pontamine skyblue dye in $0.5 \mathrm{M}$ sodium acetate glued to another glass electode filled with $3 \mathrm{~mm}$ NT. Tungsten stimulating electrodes with tip diameters of $8-15 \mu \mathrm{m}$ were placed in the $\mathrm{LH}$ and in the nucleus raphe magnus or its adjacent region, the nucleus magnocellularis. In nearly all experiments, a glass electrode containing $100 \mathrm{~mm}$ glutamic acid (monosodium L-glutamate) was glued to the stimulating electrode placed in the LH. Pressure of 1-5 psi was used to inject glutamic acid. In order to determine the conduction velocity of fibers connecting the $\mathrm{LH}$ to the PAG, a recording electrode was glued to a tungsten stimulating electrode and was placed into the $\mathrm{LH}$ and a similar electrode assembly was also placed into the PAG. The PAG region was searched until an area containing neurons responsive to $\mathrm{LH}$ stimulation was found. This area was stimulated while a recording was made from the $\mathrm{LH}$ region. Once a cell in this area was isolated, its response to $P A G$ stimulation was determined. In particular, antidromic activation of LH neurons by PAG stimulation was tested. LH neurons were considered to be antidromically activated if they responded with a constant-latency spike to high-frequency stimulation $(80-100 \mathrm{~Hz})$ of PAG and if collision between an evoked antidromic spike and a spontaneously generated action potential occurred. The latency from the onset of stimulus pulse to the peak of the antidromic spike was used for the calculation of the conduction velocity.

In the second series of experiments, a lightly anesthetized preparation was used. In this series, each animal was anesthetized with $40 \mathrm{mg} / \mathrm{kg}$ 
sodium pentobarbital and the surgical procedures described above were performed. Throughout the experiment the animal was infused with methohexital at a rate of 10 to $15 \mathrm{mg} / \mathrm{kg} / \mathrm{hr}$. The animal's tail was placed on a specially designed heater that could raise the skin temperature to a desired degree at a rate of $5^{\circ} \mathrm{C} / \mathrm{sec}$. The $\mathrm{LH}$ was stimulated electrically or by injection of glutamic acid $(200 \mathrm{~mm}, 0.1-1 \mu \mathrm{l})$, and the influence of this stimulation on tail flick (TF) latency was examined. Before each measurement the tail temperature was brought down to $25^{\circ} \mathrm{C}$. The cutoff latency was $10 \mathrm{sec}$, and if TF did not occur before this time, the current was automatically cut off and the tail was removed from the heat source. The site that inhibited TF to cut off with minimum current was selected for stimulation.

In experiments involving recording from PAG cells, this area was searched until a spontaneously firing unit was isolated. The projection of that cell to the NRM/NMC was tested by stimulation of these nuclei. The site of stimulation in the $\mathrm{LH}$ was chosen by localizing the point in $\mathrm{LH}$ that produced maximum effect on PAG neurons with minimum current intensity. In these experiments, the LH-stimulating electrode was placed in the most dorsal part of the LH and currents up to 100 $\mu \mathrm{A}$ were used to activate the region. The electrode was advanced deeper into the LH until a point that produced maximum effect with minimum current was found. The position of the stimulating electrode was fixed, and this region of the $\mathrm{LH}$ was stimulated throughout the experiment. In each experiment, after characterization of the PAG cell, its response to NT was measured. NT was applied incrementally using pressures of 2-20 psi.

The anatomical data presented here are drawn from a collection of 22 observations in which PHAL injections were made in various sites within the $\mathrm{LH}$ area. The methods used for the injection of the lectin and subsequent tissue processing follow those of Gerfin and Sawchenko (1984). Briefly, PHAL was delivered by iontophoretic injections made in male Long-Evans rats weighing between 280 and $500 \mathrm{gm}$ and anesthetized with urethane $(1 \mathrm{gm} / \mathrm{kg})$. Square-wave, positive-current pulses of $6 \mu \mathrm{A}$ amplitude and $5 \mathrm{sec}$ duration were delivered every $10 \mathrm{sec}$, with total injection times of between 20 and $60 \mathrm{~min}$. The injection pipettes were pulled from $3 \mathrm{~mm}$ borosilicate glass capillary tubes on a Canberratype vertical microelectrode puller (Narashige) and filled with $2.5 \%$ PHAL in $0.05 \mathrm{M}$ potassium PBS. The pipette tips were cut with iridectomy scissors to have diameters of between 10 and $50 \mu \mathrm{m}$.

The animals were generally allowed to survive $14 \mathrm{~d}$, although times as short as 7 and as long as $35 \mathrm{~d}$ were tried in a few cases. These longer or shorter survival times were not found to have a significant effect on the results. At the end of the survival period, the animals were given a lethal dose of urethane and perfused through the aorta with the following sequence of solutions: $250 \mathrm{ml}$ of buffered normal saline, $250 \mathrm{ml}$ of $4 \%$ freshly cracked paraformaldehyde in sodium acetate buffer, $\mathrm{pH} 6.5$, and $250 \mathrm{ml}$ of $4 \%$ paraformaldehyde plus $0.05 \%$ glutaraldehyde in sodium borate buffer, $\mathrm{pH} 9.5$. The brains were removed and stored overnight in the borate-buffered fixative. Fifty micron sagittal or coronal Vibratome (Lancer, series 1000) sections were cut and processed for immunohistochemical detection of the PHAL according to the Gerfin and Sawchenko (1984) protocol. Incubation in goat-raised primary antisera (Vector Laboratories) was for $48 \mathrm{hr}$. Subsequent detection was with the avidin-biotin-peroxidase technique (Hsu et al., 1981) using the commercially available reagent kit (Vector Laboratories). The tissue was reacted with $3^{\prime}-5^{\prime}$-diaminobenzidine as the chromagen.

\section{Results}

Activities of 60 neurons in chloral hydrate-anesthetized (deep anesthesia; DA) and 27 neurons in pentobarbital-anesthetized (light anesthesia; LA) animals were recorded. The majority of the neurons (45/60 DA and 17/27 LA) responded to noxious stimulation with excitation. These cells had baseline firing rates that ranged between 4 and 40 impulses/second. Noxious stimulation increased the firing rate $2-$ to 4 -fold. Inhibitory response to noxious stimulation was observed in $15 \%(9 / 60)$ in DA and in $11 \%(3 / 27)$ in LA animals. The mean baseline firing rate of PAG in DA animals was $9.36 \pm 8.71$ STD and in LA animals, $10.76 \pm 8.26 \mathrm{STD}$. The difference between baseline activity and the response to noxious stimulation of cells in these 2 types of preparation was not statistically significant. Since PAG neurons in these 2 types of preparations showed similar responses to LH
Table 1. Response to electrical stimulation of the LH

\begin{tabular}{lccll}
$\begin{array}{l}\text { Response to } \\
\text { glutamic acid } \\
\text { injected into } \\
\text { the LH }\end{array}$ & Excitation & Inhibition & $\begin{array}{l}\text { No } \\
\text { response }\end{array}$ & Total \\
\hline Excitation & $18(8,10)$ & $2(0,2)$ & $2(0,2)$ & 22 \\
Inhibition & $2(1,1)$ & $8(3,5)$ & $0(0,0)$ & 10 \\
No response & $5(1,4)$ & $4(3,1)$ & $6(2,4)$ & 15 \\
$\quad$ Total & 25 & 14 & 8 & 47
\end{tabular}

Responses of PAG cells that were excited by electrical stimulation and injection of glutamic acid into the lateral hypothalamus. Chi-square test shows a significant interaction between the 2 types of stimulations of LH: $\chi^{2}=7.05, d f=4,0.1<p$ $<0.25$. The numbers in parentheses show the number of neurons that were recorded in lightly anesthetized and in chloral hydrate-anesthetized preparations, respectively.

stimulation and to NT, the data obtained were pooled. Electrical stimulation of the LH with $200 \mu \mathrm{sec}$ constant cathodal current of 10-30 $\mu \mathrm{A}$ produced an excitation with onset latency of $14 \pm$ $1.7 \mathrm{msec}$ STD. In order to test the possibility that this excitatory effect was due to activation of fibers of passage, 2 types of experiments were conducted. In the first, the response of $\mathrm{LH}$ neurons to electrical stimulation of PAG was measured and the tests for antidromic activation (constant-latency, high-frequency following and the collision) were made to establish direct projection from $\mathrm{LH}$ to PAG. These procedures were used in 8 separate experiments. In the second type of study, the response of PAG cells to injection of glutamic acid [which activates cell bodies without activation of fibers of passage (Zieglgänsberger and Puil, 1973)] into the LH was tested. This procedure was used in the study of 29 cells in DA and of 18 cells in LA animals. In experiments involving the collision test, the antidromically activated spike occurred with a latency that ranged between 13 and $14.5 \mathrm{msec}$, with 2 cells responding at $13 \mathrm{msec}, 4$ neurons at $13.75 \mathrm{msec}, 1$ cell at $14 \mathrm{msec}$, and 1 cell at $14.5 \mathrm{msec}$. Figure 1 shows a poststimulus histogram constructed by measuring the responses of a PAG neuron to electrical stimulation of $\mathrm{LH}$ at 1 $\mathrm{Hz}$ for 300 sweeps. As shown, LH stimulation produced an excitatory effect with a latency to maximum response of 14 msec. The inset in Figure 1 shows the response of a $\mathrm{LH}$ neuron (located at the same site that produced excitation of PAG cell) to electrical stimulation of the PAG. As demonstrated, the LH cell was antidromically activated by PAG stimulation with a latency of $13.75 \mathrm{msec}$, indicating a direct projection of this cell to the PAG.

Injection of glutamic acid (10-100 $\mathrm{nl}$ of $200 \mathrm{~mm}$ monosodium-L-glutamate) into the $\mathrm{LH}$ produced a response in PAG cells that was comparable to their response to electrical stimulation. As shown in Table 1, glutamic acid injection in the LH produced excitation in 18 cells that were also excited by electrical stimulation and caused inhibition of 8 cells that were inhibited by electrical stimulation. However, in 5 cells that were excited and 4 cells that were inhibited by electrical stimulation, glutamic acid injection produced no response. This observation indicates that some of the effect of LH stimulation on PAG cells is through activation of axons of passage, but the majority of the response is due to activation of the cell bodies in the LH. In 47 cells, the responses to electrical stimulation of LH (200 $\mu \mathrm{sec}$ constant-current pulses with intensities of up to $40 \mu \mathrm{A}$ at frequencies of 100 and $200 \mathrm{~Hz}$ for a period of $1 \mathrm{sec}$ ) and to microinjection of glutamic acid into the $\mathrm{LH}$ were compared with 
Figure 1. Poststimulus histogram constructed by recording the response of a PAG cell to electrical stimulation of the $\mathrm{LH}$ with constant-current cathodal pulses of $200 \mu \mathrm{sec}$ in duration and an intensity of $20 \mu \mathrm{A}$ applied at a frequency of $1 \mathrm{~Hz}$ for 300 sweeps. Inset, Response of a cell in the $\mathrm{LH}$ at the site that produced excitation of PAG to electrical stimulation of PAG. This cell was antidromically activated with a latency of $13.75 \mathrm{msec}$ and could be backfired by PAG stimulation at $80 \mathrm{~Hz}$. Abolition of an antidromically activated spike by a spontaneous action potential indicates collision of the anti- and spontaneous orthodromic action potentials. These satisfy the criteria for antidromic activation and demonstrate a direct projection from $\mathrm{LH}$ to PAG.

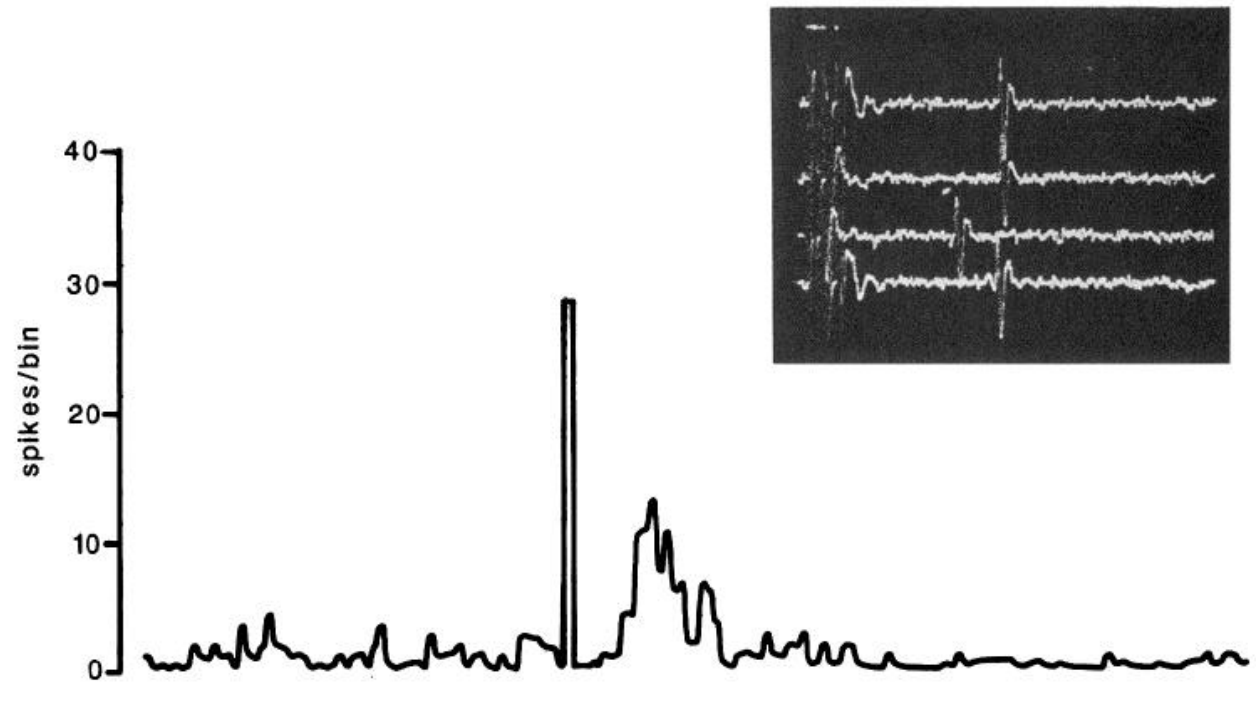

$14 \mathrm{msec}$ their responses to pressure injection of NT. Table 2 summarizes the results obtained in these experiments. As indicated, the majority of the PAG cells (37/47) were excited by NT. Although in $12 \%$ of the neurons (6/47), NT and stimulation of LH produced opposite effects, there was a strong correlation between excitatory responses produced by NT injection and LH stimulation.

The effect of NT was dose dependent. Increasing the dose of NT produced progressively stronger and longer-lasting excitation of PAG neurons. Figure 2 shows this property of the NT effect and its similarity to the response of PAG cells to electrical stimulation of the LH. As indicated in Figure 2, NT injected at 2 psi for $30 \mathrm{sec}$ produced an increase in the firing rate from mean of $7 / \mathrm{sec}$ to $12 / \mathrm{sec}$ that lasted for $60 \mathrm{sec}$. When the injection pressure was increased to $4 \mathrm{psi}$, NT injection increased the firing rate to $20 / \mathrm{sec}$, and the effect lasted for $120 \mathrm{sec}$. Electrical stimulation of $\mathrm{LH}$ with a train of pulses at frequencies of 100 and
$200 \mathrm{~Hz}$ for $1 \mathrm{sec}$ produced an excitation that was comparable to the excitation produced by NT.

In 32 cells, the time course of excitation of PAG cells produced by electrical stimulation or injection of glutamic acid into the LH was similar to that of the response to NT injection. Figure 3 shows the responses of a PAG cell to electrical stimulation of $\mathrm{LH}$, injection of glutamic acid into the $\mathrm{LH}$, and pressure injection of NT next to the cell in the PAG. As shown, all 3 manipulations produced long-lasting excitation of this neuron. The time courses of the response of PAG cells to electrical (train stimulation, $200 \mu \mathrm{sec}$ pulses for $100 \mathrm{msec}$ at 100 and $200 \mathrm{~Hz}$ ) and glutamic acid stimulation of the LH were very similar to the response of these cells to NT. In the majority of cells, LH stimulation produced an excitatory response that lasted for several minutes. As indicated in Figure 3, there was a slight inhibition of the firing rate of the PAG cell immediately after injection of glutamic acid into and electrical stimulation of the
Figure 2. Responses of a PAG neuron to neurotensin (NT) and to electrical stimulation of the lateral hypothalamus (LH). Pressure injection of NT produced an excitatory and dose-dependent effect. NT at 2 psi produced an cxcitation that lasted for $40 \mathrm{sec}$, whereas NT applied at $4 \mathrm{psi}$ produced an excitation that lasted for $210 \mathrm{sec}$. The same neuron was excited when LH was stimulated with $20 \mu \mathrm{A}$ pulses at $100 \mathrm{~Hz}$.

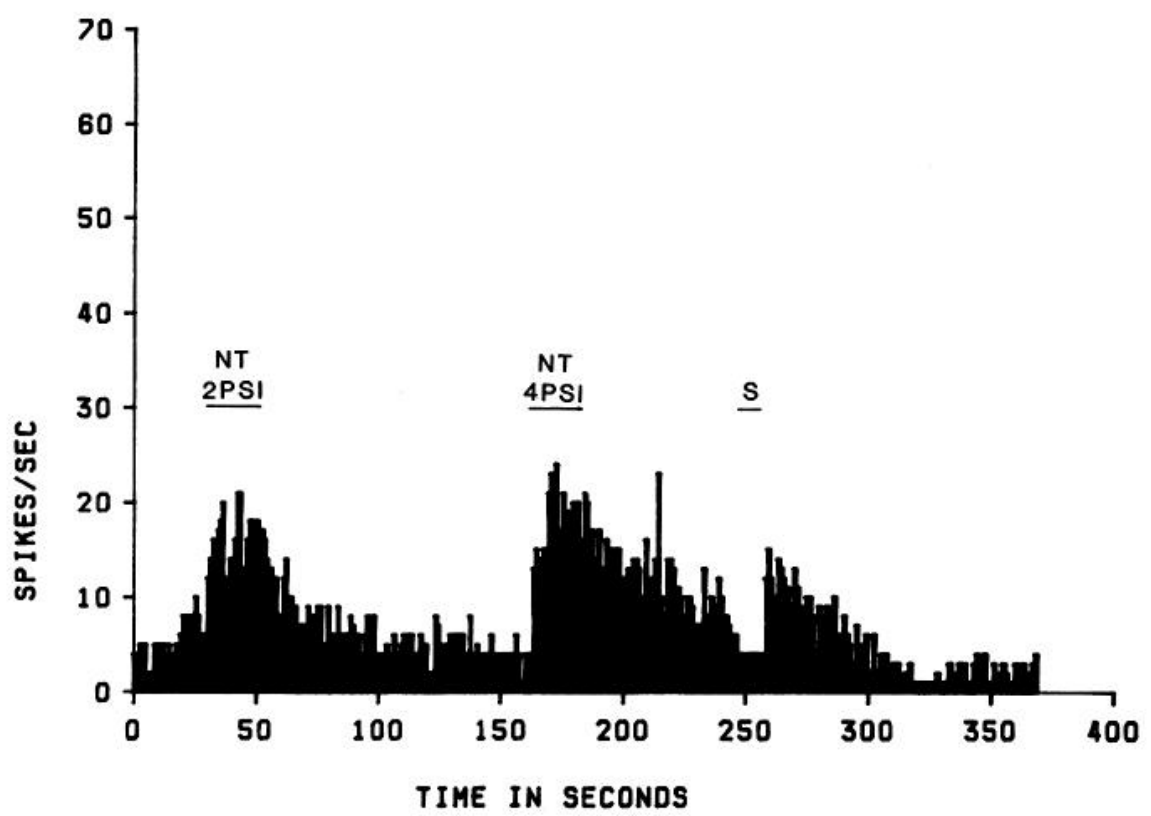



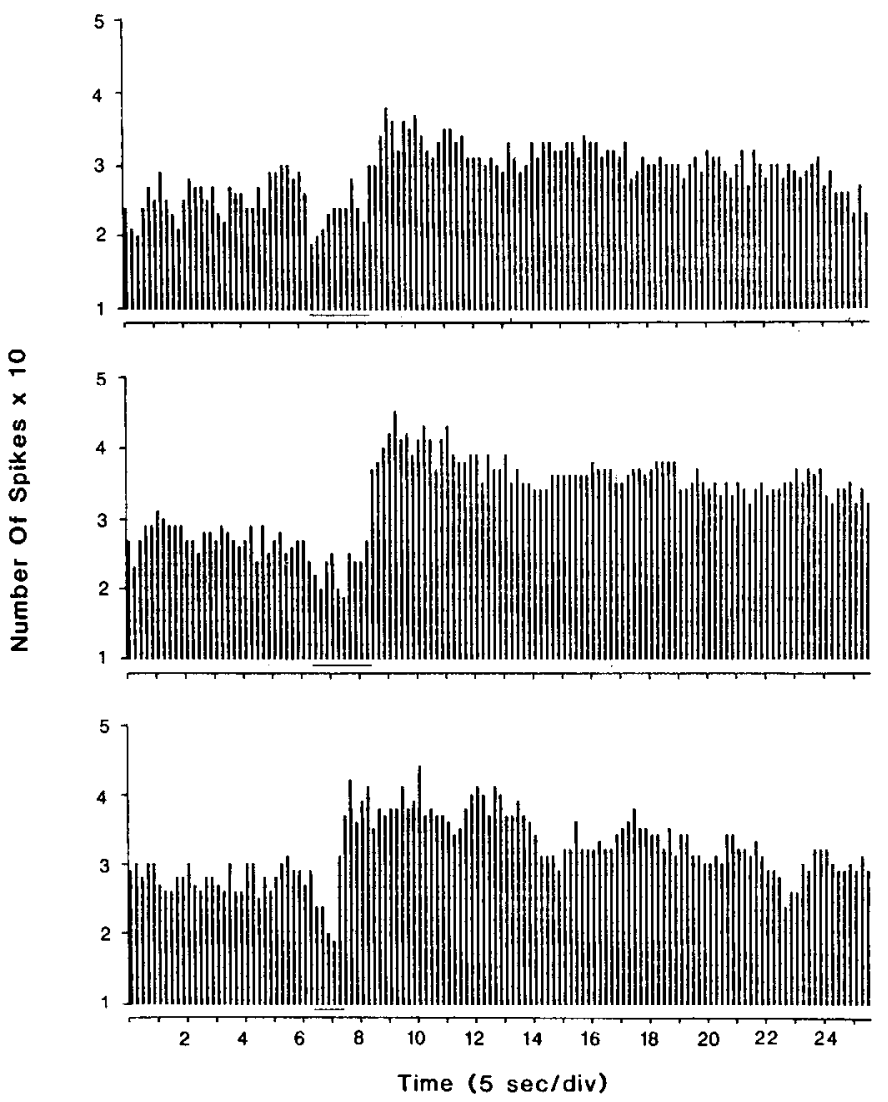

Figure 3. Comparison of the responses of a PAG neuron to electrical stimulation of $\mathrm{LH}$, to injection of glutamic acid into the $\mathrm{LH}$, and the response to NT. Top, Shows the response of a PAG cell to $10 \mathrm{sec}$ stimulation of $\mathrm{LH}$ with $20 \mu \mathrm{A}$ depolarizing pulses at $100 \mathrm{~Hz}$. Middle, Response of the same cell to injection of $10-20 \mathrm{nl}$ of $100 \mathrm{~mm}$ glutamic acid into the LH. Bottom, Response of the cell to NT applied with a pressure of $5 \mathrm{psi}$ for $5 \mathrm{sec}$. The activity of the cell during the electrical stimulation, as indicated by a bar under each figure, does not truly represent the firing pattern of the cell because the first millisecond after each pulse was ignored by the program in order to delete the stimulus artifact. The response to glutamic acid was obtained $7 \mathrm{~min}$ after the response to electrical stimulation was measured. The response to NT was measured $10 \mathrm{~min}$ after the response to glutamic acid was measured.

LH. This type of response was observed in only 11 other cells. However, the degree of inhibition was not uniform and was not statistically significant when all neurons were considered.

In $14 \mathrm{LA}$ animals, stimulation of $\mathrm{LH}$ inhibited TF to cut-off latency of $10 \mathrm{sec}$. This inhibition was time dependent and was related to the frequency and strength of the stimulus. In all cases, the site that produced inhibition of TF and the sites that were most effective in alteration of firing rate of PAG neurons were nearly identical. At the lowest current $(<50 \mu \mathrm{A})$, TF inhibition by $\mathrm{LH}$ stimulation occurred only during the stimulation, and TF latency returned to baseline as soon as the LH stimulation stopped. When the current intensity was increased to $80 \mu \mathrm{A}$, TF inhibition outlasted the stimulation time by at least $20 \mathrm{sec}$. Injections of glutamic acid in LH produced TF inhibition that outlasted the injection period for as long as $1.5 \mathrm{~min}$. The increase in the firing rate of PAG cells, however, always exceeded the duration of LH stimulation.

Stimulation of a hypothalamic area dorsal to the LH also produced analgesia as measured by inhibition of TF. However, the current intensity required to produce this effect was variable. As shown in Figure $4 B$, a current intensity of $160 \mu \mathrm{A}$ was re-
Table 2. Response to electrical stimulation of or glutamic acid injected into the LH

\begin{tabular}{lllll}
$\begin{array}{l}\text { Response to } \\
\text { neurotensin } \\
\text { applied to }\end{array}$ & Excitation & Inhibition & $\begin{array}{l}\text { No } \\
\text { response }\end{array}$ & Total \\
\hline PAG & $32(6,26)$ & $4(1,3)$ & $1(1,0)$ & 37 \\
\hline Excitation & $2(0,2)$ & $2(0,2)$ & $0(0,0)$ & 4 \\
Inhibition & $4(1,3)$ & $1(0,1)$ & $1(1,0)$ & 6 \\
No response & 38 & 7 & 2 & 47 \\
Total & & & 2 &
\end{tabular}

Responses of PAG neurons to electrical or glutamic acid stimulation of the lateral hypothalamus and to micropressure injection of NT into the PAG. Numbers in the parentheses show the number of neurons that were recorded in the lightly anesthetized and chloral hydrate-anesthetized preparations respectively. Chi-square tests show significant interaction between the response to $\mathrm{LH}$ stimulation and to $\mathrm{NT}: \chi^{2}=25.42, d f=4,0.0005<p<0.001$.

quired to produce inhibition of TF when a region $1 \mathrm{~mm}$ dorsal to LH was stimulated, whereas a current intensity of $40 \mu \mathrm{A}$ was needed to block TF when LH was stimulated. The location of the PAG cells that were responsive to $\mathrm{LH}$ stimulation is shown in Figure $4 A$. These cells were located in the ventromedial and the ventrolateral PAG.

Injections of PHAL at all rostrocaudal levels of $\mathrm{LH}$ produced terminal labeling in the ipsilateral PAG. The criteria for terminal fields are the presence of axonal varicosities and varicositycontaining short branches (e.g., Fig. 5, $A, B$ ). Figure 6 shows the distribution of PHAL-labeled axons and terminals in a representative case. Labeled processes meeting the criteria for terminal fields are indicated as dotted line segments in the plots in Figure 6. These plots are at the levels corresponding to the recording sites in PAG (Fig. 4A), at the level of the decussation of the superior cerebellar peduncle (Fig. $6 \mathrm{C}$ ), and $1 \mathrm{~mm}$ rostral to that point, at a rostrocaudal level that passes through the rostral oculomotor nucleus (Fig. $6 B$ ). The injection site in rostral LH is shown in Figure $6 \mathrm{~A}$. A high-power photomicrograph of this injection site is portrayed in Figure $4 D$, illustrating the complete, Golgi-like filling of the neurons that give rise to the labeled axons in PAG and other efferent targets. Another example of axon terminal labeling in PAG produced from a PHAL injection is shown in Figure $4, A$ and $C$. These 2 injection sites in the rostral LH correspond to the stimulation sites used in the physiology experiments (Fig. 4B). LH terminal fields are uniformly distributed throughout the ventral two-thirds of the ipsilateral PAG and spread into the adjacent dorsal raphe nucleus.

LH axons reach mesencephalic and brain-stem periaqueductal structures by 2 routes. After passing caudally through the medial forebrain bundle, the dorsal pathway takes a direct line dorsally through the fields of Forel to reach the regions surrounding the mesencephalic aqueduct. The ventral pathway remains in the medial forebrain bundle until it reaches the mesencephalon just dorsal and caudal to the interpeduncular nucleus. The fibers then take a dorsal and caudal course through the tegmentum to reach PAG. Fibers of the ventral pathway are particularly evident in Figure $5 B$ as they pass through midline raphe nuclei, which they innervate, and more laterally as a separate bundle in the retrorubral field.

Using the light microscope, we estimate the diameter of the LH-PAG axons to range between 0.3 and $0.8 \mu \mathrm{m}$. The lower value is close to the limit of resolution of the light microscope and so should be considered only approximate. 

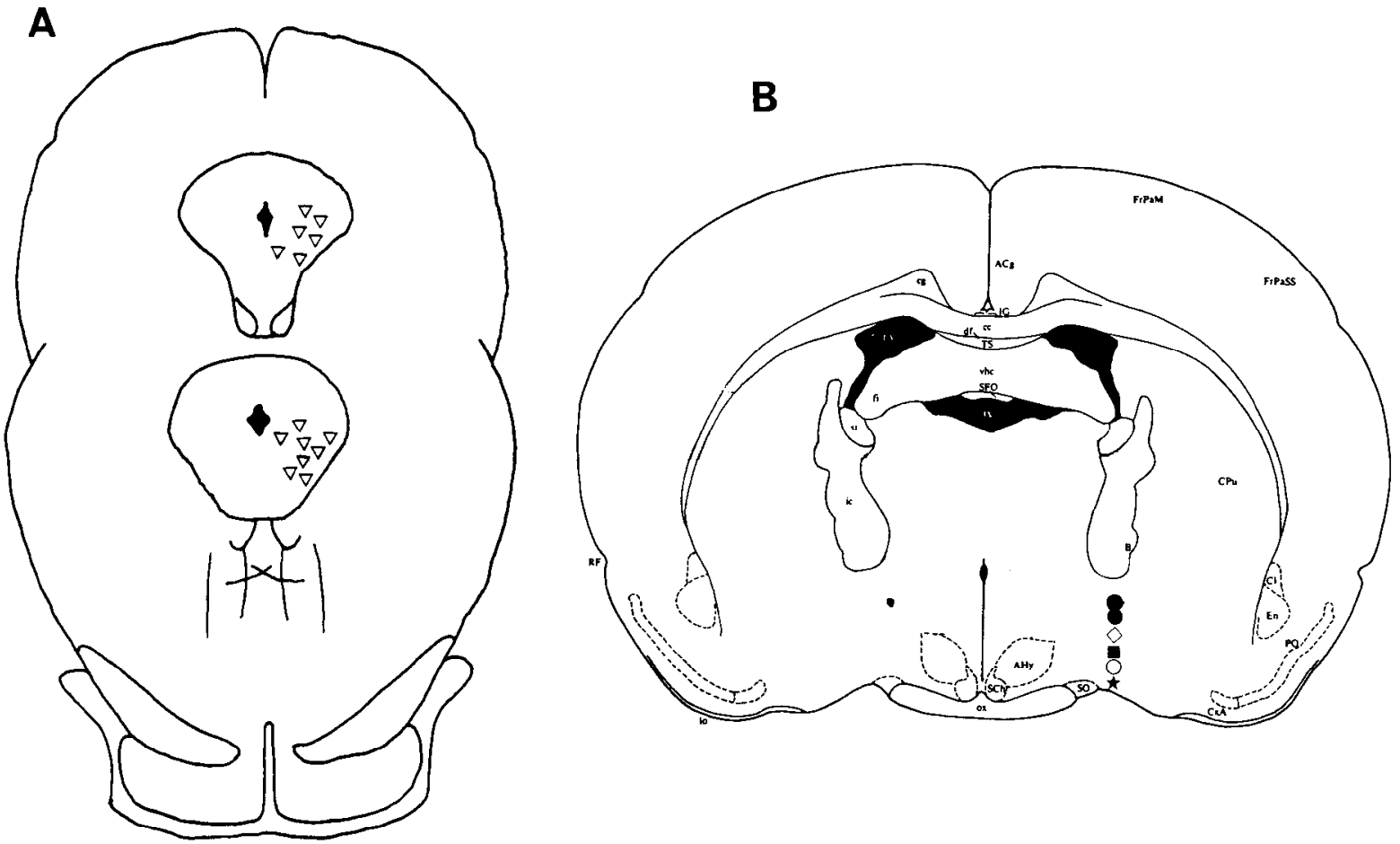

Figure 4. A, Locations within PAG of cells that responded to NT. As indicated, the majority of these neurons were situated in the lateral and the ventrolateral parts of the PAG. $B$, Regions of the LH where electrical stimulation or injection of glutamic acid produced changes in the firing rate of the PAG cells. As indicated, the threshold for tail flick inhibition was the lowest when the electrode was in the medial part of the LH, about $300 \mu \mathrm{m}$ dorsal to the optic tract. Symbols identify the minimum current intensity that produced analgesia., $100 \mu \mathrm{A} ; \diamond, 60 \mu \mathrm{A} ; \mathbf{\square}, 50 \mu \mathrm{A} ; O 40$ $\mu \mathrm{A} ; \star, 60 \mu \mathrm{A}$

\section{Discussion}

The results of these experiments indicate that activation of the LH can produce analgesia. These results are in agreement with results obtained by Carr and Coons (1982), in which stimulation of LH inhibited escape behavior induced by electrical stimulation of nucleus gigantocellularis. Several studies (Cox and Valenstein, 1965; Rose, 1974; Carr and Uysal, 1985), including the aforementioned investigation, have suggested that LH stimulation activates neuronal networks that are involved in supraspinal modulation of pain. Our observations suggest that interactions between $\mathrm{LH}$ and PAG can possibly be the network involved in this action of $\mathrm{LH}$.

The majority of PAG neurons recorded in this study were excited by stimulation of the lateral hypothalamus. Comparison of the responses of these cells to electrical stimulation of $\mathrm{I} . \mathrm{H}$ and to injection of glutamic acid in this region showed comparable response characteristics. Since glutamic acid acts on the cell bodies and does not activate axons (Zieglgänsberger and Puil, 1973), these data indicate that the effect of LH stimulation on PAG cells is mediated through activation of the cell bodies rather than axons of passage. These results are consistent with the observation of monosynaptic excitatory postsynaptic potentials in dorsal raphe neurons evoked by stimulation of $\mathrm{LH}$ (Park, 1985).

We have shown that anterogradely labeled $\mathrm{LH}$ axons form terminal fields in those portions of PAG in which excitatory LH evoked responses have been recorded. This anatomical result using the new PHAL technique confirms observations from previous tract-tracing studies that employed amino acid autoradiographic techniques (Saper et al., 1979; Hosoya and Ma- tsushita, 1981; Berk and Finkelstein, 1982). The PHAL technique provides the additional information of axon diameter, as well as greater security in distinguishing terminal fields from axons of passage.

Of the 2 pathways taken by LH efferent fibers, the trajectory of the dorsal one is nearly linear, and so its length is well approximated by the straight line distance between stimulation and recording sites. Using the stereotaxic atlas of Paxinos and Watson (1982) as a standard for determining the Cartesian coordinates of stimulation and recording sites, the straight line distances are 7.1 and $6.4 \mathrm{~mm}$ for the 2 sets of stimulation sites shown in Figure $4 B$. The ventral pathway passes just rostral to the interpeduncular nucleus and has a length of $8.0 \mathrm{~mm}$ in the Paxinos and Watson rat. The mean latency of the excitatory response recorded in PAG and the antidromic responses evoked in LH by stimulation of PAG is $14 \mathrm{msec}$, which yields conduction velocities of $0.5,0.5$, and $0.6 \mathrm{~m} / \mathrm{sec}$ for the 3 distances given. Conduction velocities of this magnitude are consistent with unmyelinated or myelinated fibers less than $1 \mu \mathrm{m}$ in diameter (Waxman and Bennett, 1972) and are quite consistent with the fiber sizes of $0.3-0.8 \mu \mathrm{m}$ seen in the PHAL-labeled material.

The responses of PAG cells to NT and to stimulation of LH were compared. NT had a predominantly excitatory effect. This is in agreement with results obtained previously in this laboratory (Behbehani and Pert, 1984) and by other investigators (Stanzione and Zieglgänsberger, 1983; Herbison et al., 1986). As indicated in Table 2, there is a strong correlation between these responses. Specifically, if the duration of the response is considered, a close resemblance exists between the time course of the response to LH stimulation and to NT. This suggests that 

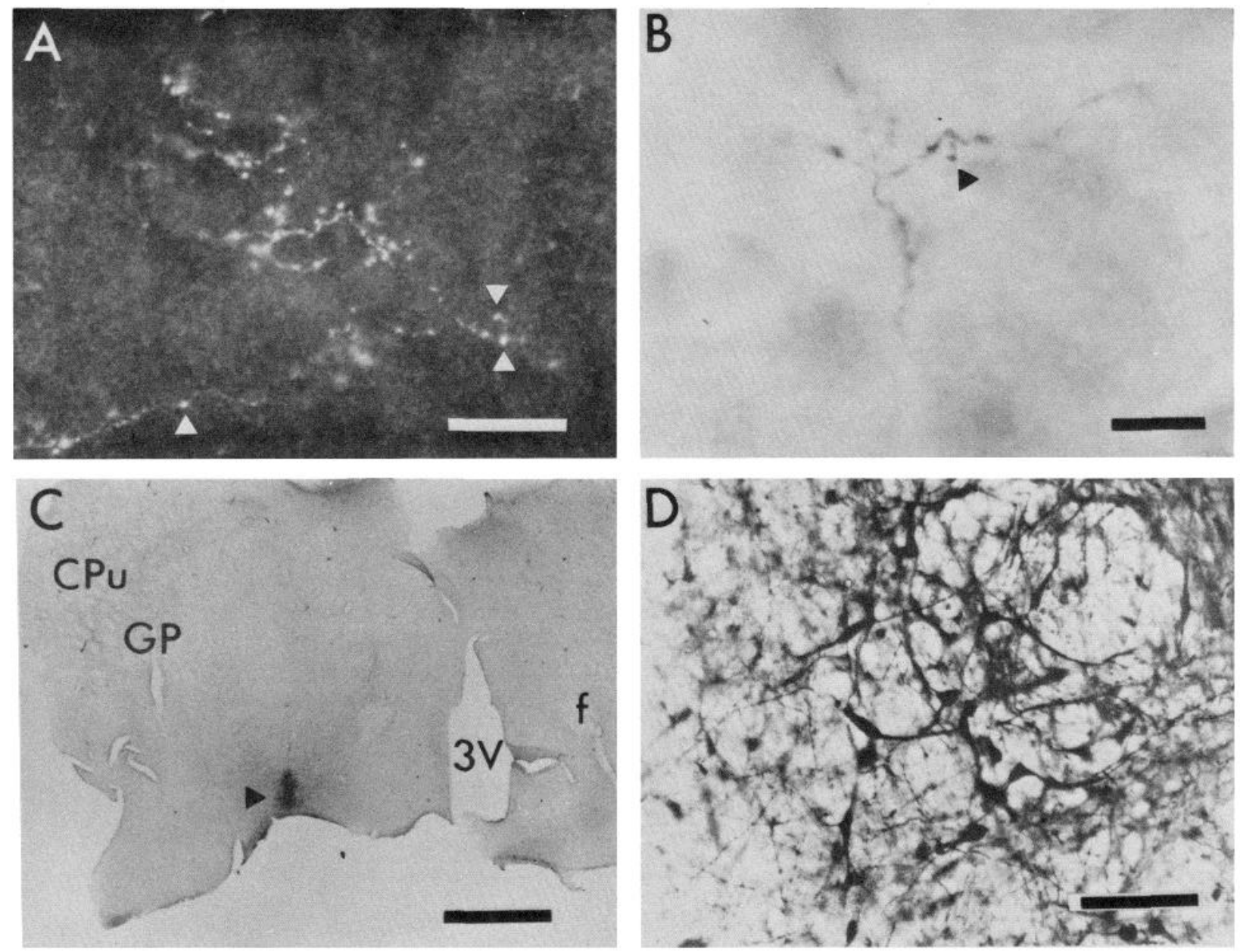

Figure 5. PHAL-labeled terminal fields in PAG. A, Dark-field photomicrograph of axons in PAG found to be filled with PHAL following an injection (shown in $D$ ) in rostral LH. Numerous varicosities suggestive of presynaptic terminals stud the labeled axons. The arrowheads point to 3 examples: along the course of a nonbranching axon (left arrowhead) and at the branching and end of a short terminal branch (right arrowheads). Additionally, each small bright point in the field stretching from the center to upper left of the photomicrograph is an axonal varicosity. Scale bar, $30 \mu \mathrm{m}$. B. Bright-field photomicrograph of an axonal terminal field in PAG. The arrowhead indicates a varicosity at the end of a short axonal twig. This is the same case as shown in Figure 6. Scale bar, $10 \mu \mathrm{m}$. $C$, Injection site in LH. Terminals in PAG from this injection are shown in $A$. The arrowhead points to the PHAL injection site in rostral LH. Abbreviations: $C P u$, caudate putamen; $G P$, globus pallidus; $3 \mathrm{~V}$, third ventricle; $f$, fornix. Scale bar, $1.0 \mathrm{~mm}$. D, Magnified view of a typical PHAL injection site in LH. Individual neurons that have Golgi-like filling are evident. This is the same case that is shown in $B$ and in Figure 6. Scale bar, $50 \mu \mathrm{m}$.

a neurotensinergic pathway may mediate the interaction between these 2 sites. However, since a neurotensin antagonist is not currently available, this hypothesis could not be tested directly.

In the lightly anesthetized preparation, stimulation of the $\mathrm{LH}$ produced TF inhibition that outlasted the stimulus by as long as $2 \mathrm{~min}$. This result is similar to that reported by Carstens et al. (1983) and by Cox and Valenstein (1965). The electrically induced increase in TF latency we observed is also in agreement with more recent observations by Aimone and Gebhart (1987). However, in their studies, injection of glutamic acid did not cause a change in TF latency, whereas in this study glutamic acid injection in the $\mathrm{LH}$ produced as strong an effect as electrical stimulation on TF latency. The reason for this discrepancy is not clear. One possible reason is that the site of injection in this study was more lateral than in those reported by Aimone and Gebhart.

It has been suggested that the analgesic effect of LH stimulation can be due to activation of fibers of passage that travel through the medial forebrain bundle and terminate in PAG, NRM, and the dorsolateral pons. Our anatomical and glutamic acid injection experiments suggest that there is a direct projection from cells in the LH to the PAG, and it is therefore likely that activation of this pathway also contributes to the analgesia produced by stimulation of the LH. However, lesion studies (either by injection of local anesthetic or electrolytic lesioning) will be required to establish this point. The existence of such a strong interaction between LH and PAG supports the hypothesis that, under natural conditions, PAG activation may be due to activation of limbic system-LH pathway (Sandrew and Poletti, 1984).

In the LA preparation, few neurons decreased their firing rate just prior to the TF. These types of neurons have been observed by Heinricher et al. (1987) and have been characterized as Offcells. In our experiments, these cells were strongly excited by LH stimulation as well as by NT.

Comparisons of the baseline firing rates and responses of PAG neurons showed no significant difference between LA and DA 
Figure 6. Plot of axonal labeling following an injection of PHAL in LH. $A$, The portion of the injection site that contained intracellularly labeled neuronal somata is indicated by the dots and a central region (black) of dense labeling. Neurophil staining extended throughout the outlined area having diagonal striations. The short line segments indicate PHAL-labeled fibers leaving the injection site. $B$ and $C$, Coronal sections through PAG that correspond to the level in which single-unit recordings were made. Terminal fields are evident in PAG ipsilateral to the injection sitc. Abbrcviations: 3, oculomotor nucleus; $3 V$, third ventricle; $A q$, mesencephalic aqueduct; $A r C$, arcuate nucleus; $C M$, center median nucleus; $c p$, cerebral peduncle; $C P u$, caudateputamen; $f$, fornix; $H b$, habenula; $i c$, internal capsule; $I P$, interpeduncular nucleus; $L H$, lateral hypothalamic area; $M e 5$, mescencephalic trigeminal nucleus; $m l$, medial lemniscus; $m l f$, medial longitudinal fasc; $S N$, substantia nigra; opt, optic tract; $P A G$, periaqueductal gray; $R t$, reticular thalamic nucleus; $V L$, ventral lateral nucleus; $V P L$, ventral postcrior latcral nuclcus; $x s c p$, decussation of the superior cerebellar peduncle.
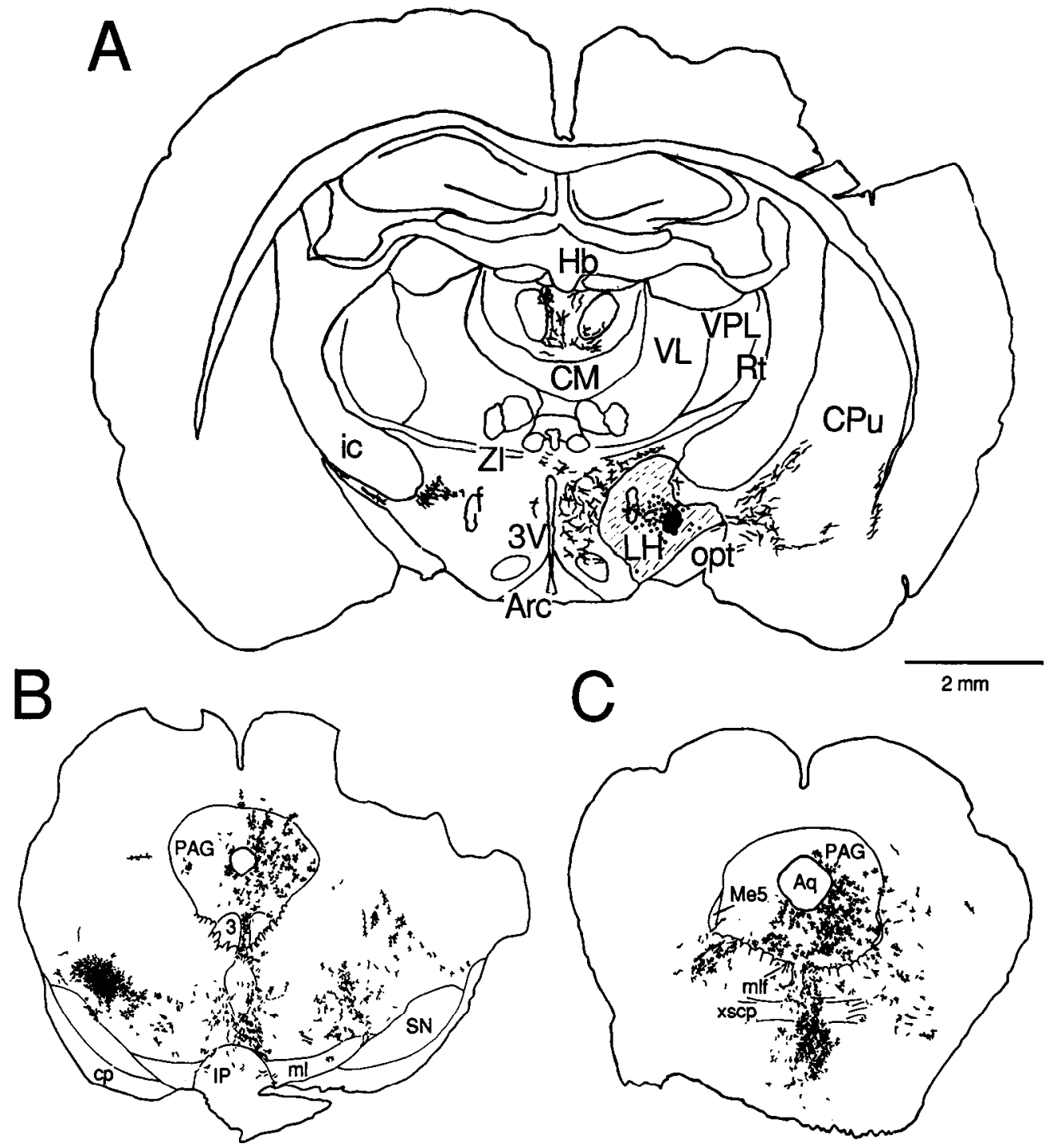

animals. This observation implies that chloral hydrate anesthesia does not profoundly affect the response characteristics of PAG cells and can be a useful anesthetic agent in studies of descending pain inhibitory pathways.

\section{References}

Aimone, L. D., and G. F. Gebhart (1987) Spinal monoamine mediation of stimulation-produced antinociception from the lateral hypothalamus. Brain Res. 403: 290-300.

Basbaum, A. I., N. Mrley, J. O'Keefe, and C. H. Clanton (1977) Reversal of morphine and stimulus produced analgesia by subtotal spinal cord lesion. Pain 3: 43-56.

Basbaum, A. I. C. H. Clanton, and H. L. Fields (1978) Three bulbospinal pathways from the rostral medulla of the cat. An autoradiographic study of pain modulating system. J. Comp. Neurol. I: 209-224.

Behbehani, M. M., and H. L. Fields (1979) Evidence that an excitatory connection between the periaqueductal grey and nucleus raphe magnus mediates stimulation produced analgesia. Brain Res. 170:85-93.

Behbehani, M. M., and A. Pert (1984) A mechanism for the analgesic effect of neurotensin as revealed by behavioral and electrophysiological studies. Brain Res. 292: 207-220.

Beitz, A. J. (1982) The organization of afferent projections to the midbrain periaqueductal grey of the rat. Neuroscience 7: 133-159.

Bennett, G. J., and D. J. Mayer (1979) Inhibition of spinal cord interneurons by narcotic microinjection and focal electrical stimulation in the periaqueductal central gray matter. Brain Res. 172: 243-258.

Berk, M. L., and J. A. Finkelstein (1982) Efferent connections of the lateral hypothalamic area of the rat: An autoradiographic investigation. Brain Res. Bull. 8: 511-526.

Carr, K. D., and E. E. Coons (1982) Lateral hypothalamic stimulation gates nucleus gigantocellularis-induced aversion via a reward-independent process. Brain Res. 232: 293-316.

Carr, K. D., and S. Uysal (1985) Evidence of a supraspinal opioid analgesic mechanism engaged by lateral hypothalamic electrical stimulation. Brain Res. 335: 55-62.

Carstens, E., M. Fraunhoffer, and S. N. Suberg (1983) Inhibition of spinal dorsal horn neuronal responses to noxious skin heating by lateral hypothalamic stimulation in the cat. J. Neurophysiol. 50: 192204.

Cox, V. C., and E. S. Valenstein (1965) Attentuation of aversive properties of peripheral shock by hypothalamic stimulation. Science 149: 323-325.

Fields, H. L., J. Bry, I. Hentall, and G. Zorman (1983) The activity of neurons in the rostra medulla of the rat during withdrawal from noxious heat. J. Neurosci. 3: 2545-2552.

Gebhart, G. F., J. Sandkuhler, J. G. Thalhammer, and M. Zimmermann (1983) Quantitative comparison of inhibition in the spinal cord of nociceptive information by electrical stimulation in the periaqueductal gray and nucleus raphe magnus of the cat. J. Neurophysiol. 50: $1433-1445$.

Gerfin, C. R., and P. E. Sawchenko (1984) An anterograde neuroanatomical tracing method that shows detailed morphology of neurons, 
their axons and terminals: Immunohistochemical localization of an axonally transported plant lectin, Phaseolus vulgaris leucoagglutinin (PHA-L). Brain Res. 290: 219-238.

Grofova, I., O. P. Ottersen, and E. Rinvik (1978) Mesencephalic and diencephalic afferents to the superior colliculus and periaqueductal grey substance demonstrated by retrograde axonal transport of horseradish perioxidase in the cat. Brain Res. 146: 205-220.

Heinricher, M. M., Z. F. Cheng, and H. L. Fields (1987) Evidence for two classes of nociceptive modulating neurons in the periaqueductal gray. J. Neurosci. 7: 271-278.

Herbison, A. E., J. I. Hubbard, and N. E. Sirett (1986) Neurotensin excites neurons in the arcuate nucleus of the rat hypothalamus in vitro. Brain Res. 346: 391-395.

Hosoya, Y., and M. Matsushita (1981) Brainstem projections from the lateral hypothalamic area in the rat, as studied with autoradiography. Neurosci. Lett. 24: 111-116.

Hsu, S., L. Raine, and H. Fanger (1981) Use of avidin-biotin-peroxidase complex (ABC) in immunoperoxidase techniques: A comparison between $\mathrm{ABC}$ and unlabeled antibody (PAP) procedures. J. Histochem. Cytochem. 29:577-580.

Jennes, L., W. E. Stumpf, and P. W. Kalivas (1982) Neurotensin: Topographical distribution in rat brain by immunohistochemistry. $J$. Comp. Neurol. 210: 211-224.

Kahn, D., G. M. Abrams, E. A. Zimmermann, R. Carraway; and S. E. Leeman (1980) Neurotensin neurons in the rat hypothalamus. An immunocytochemical study. Endocrinology 107: 47-54.

Krieger, M. S., L. C. A. Conrad, and D. W. Pfaff (1979) An autoradiographic study of the efferent connections of the ventromedial nucleus of the hypothalamus. J. Comp. Ncurol. 183: 785-816.

Mantyh, P. W. (1982) Forebrain projections to the periaqueductal grey in the monkey with observations in the cat and rat. J. Comp. Neurol. 204: 349-363.
Mayer, D. J., T. L. Wolfe, H. $\Lambda$ kil, B. Carder, and J. C. Liebeskind (1971) Analgesia from electrical stimulation in the brainstem of the rat. Science 174: 1351-1354.

Park, M. R. (1985) The lateral hypothalamic projection to dorsal raphe is excitatory. Soc. Neurosci. Abstr. 11: 1227.

Paxinos, G., and C. Watson (1982) The Rat Brain in Stereotaxis Coordinates, Academic, New York.

Reynolds, D. V. (1969) Surgery in the rat during electrical analgesia induced by focal brain stimulation. Science 164: 444-445.

Rose, M. D. (1974) Pain-reducing properties of rewarding electrical brain stimulation in the rat. J. Comp. Physiol. Psychol. 87: 607-617.

Sandkuhler, J., and G. F. Gebhart (1985) Characterization of inhibition of a spinal nociceptive reflex by stimulation medially and laterally in the midbrain and medulla in the pentobarbital-anesthetized rat. Brain Res. 305: 67-76.

Sandrew, B. B., and C. E. Poletti (1984) Limbic influence on the periaqueductal gray: A single unit study in the awake squirrel monkey. Brain Res. 303: 77-86.

Saper, C. B., L. W. Swanson, and W. M. Cowan (1979) An autoradiographic study of the efferent connections of the lateral hypothalamic area in the rat. J. Comp. Neurol. 183: 689-706.

Shipley, M. T., J. H. McLean, and M. M. Behbehani (1985) Distribution of neurotensin-like immunoreactive fibers in the periaqueductal gray of the rat. Soc. Neurosci. Abstr.

Stanzione, P., and W. Zieglgänsberger (1983) Action of neurotensin on spinal cord neurons in the rat. Brain Res. 268: 111-118.

Waxman, S. G., and M. V. L. Bennett (1972) Relative conduction velocities of small myelinated and non-myelinated fibres in the central nervous system. Nature [New Biol.] 238: 217-219.

Zieglgänsberger, W., and E. A. Puil (1973) Action of glutamic acid on spinal neurones. Exp. Brain Res. 17: 35-49. 